\title{
П.В. Дурягин
}

\section{НЕПОЛНАЯ НЕЙТРАЛИЗАЦИЯ КАК РЕЗУЛЬТАТ АССИМИЛЯЦИИ МЯГКИХ «СВИСТЯЩИХ» «ШИПЯЩИМИ» В ПОЗИЦИИ ВНЕШНЕГО САНДХИ В РУССКОМ ЯЗЫКЕ}

\begin{abstract}
Настоящее экспериментальное исследование посвящено результатам ассимиляции мягких переднеязычных щелевых согласных по месту образования на стыках слов в русском языке. Эксперимент показал, что щелевой согласный, образующийся в результате ассимиляции на месте сочетания /c'\#ш'/, сохраняет избыточную длительность по сравнению с одиночнылм мягким «иипящим», однако при восприятии носители не пользуются этими различиями. Это явление может быть описано как пример неполной нейтрализации.

Ключевые слова: современный русский язык, фонетика, внешнее сандхи, коартикуляцุия, щелевые согласные, ассимиляция по месту образования, неполная нейтрализация.
\end{abstract}

\section{1. Введение}

Мягкие фрикативные передненебные («шипящие») согласные в описаниях фонетики современного русского литературного языка (далее - СРЛЯ) традиционно характеризуются как долгие, или двойные. Это связано с тем, что в позиции абсолютного начала фонетического слова и в интервокальной позиции носители литературного произношения регулярно произносят долгий мягкий «шипящий» звук ${ }^{1}$ [2. С. 66-67]. Необходимо, однако, заметить, что недавнее исследование акустических характеристик переднеязычных щелевых согласных СРЛЯ показало, что даже в указанных позициях длительность фрикативного шума лишь незначительно отличает [ш':] от [ш], [c] и [c']. Эксперимент, проведенный на материале записей 10 носителей СРЛЯ в возрасте от 16 до 29 лет, показал, что абсолютная разница в длительности между [ш':] и другими переднеязычными щелевыми составляет в среднем не более 20 мс; длительность мягкого «шипящего» превышает длительность [ш] лишь на 9\% [3. С. 10-11].

При этом известно, что в остальных позициях «двойной характер согласного (т. е. долгота) может быть менее заметен, а в беглой речи даже утратиться» [4. С. 113]. Описывая сокращение долготы мягкого «шипящего», Р.И. Аванесов связывал утрату этим согласным долготы с его позицией относительно слоговой границы (по его мнению, долгий [ш':] был возможен в

${ }^{1}$ В отличие от [ш':] звонкий мягкий «шипящий» [ж’:] в СРЛЯ встречается только в этих позициях. Объектом настоящего исследования был только глухой согласный, поскольку произношение [ж’:], «которое вытесняется произношением [жж]» [1. С. 987], отсутствует в речи участников проведенного эксперимента, носителей младшей нормы. Далее в работе при использовании термина «мягкий шипящий» имеется в виду только [ш'(:)]. 
позиции после согласного, если мягкий «шипящий» начинал собой следую-

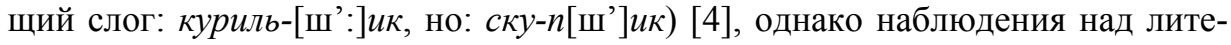
ратурным произношением начала XXI в. скорее подтверждают точку зрения о том, что утрата долготы мягким «шипящим» непосредственно связана с соседством другого согласного и не зависит от слоговой структуры [2. С. 67]. Действительно, в СРЛЯ последовательно действует коартикуляционное правило, согласно которому «невозможен долгий согласный рядом с другим согласным». В частности, «невозможен согласный «тройной долготы»... Поэтому невозможны удлиненные [ш':] и [ж’:]» [5. С. 87]. Для целей настоящего исследования важно указание М.В. Панова на то, что граница фонетического слова не является преградой для действия этого правила: во фразе Олени уж сшиблись рогами произносится «не тройной, а двойной [ш:]» [Там же].

В том случае, если акустическое различие между сочетаниями двух и трех одинаковых согласных не может быть достигнуто за счет темпоральных характеристик, возникают возможности для нейтрализации, а именно реализации согласного «нулем звука». Пример такого рода (с утратой мягкого «шипящего» на фонетическом уровне) приводит М.В. Панов: «Сочетание слов товарищ Щенгра (и подобное) в естественной речи обычно слышится и осознается как товарищ Энгра» [Там же]. Вероятно, именно для исключения возможности подобной нейтрализации в СРЛЯ в позиции перед начальным корневым [ш':], несмотря на некоторые наблюдаемые колебания, чаще используется вокализованный вариант приставки с- (сощурился, сощипнул) и предлога $c$ (со щзитом, со щеткой), при том что невокализованный вариант выступает в позиции перед твердым «шипящим» (с шипом, сшил); также вариант без гласного используют все остальные приставки и предлоги на $-c$ (расщзепил, без щчита) $)^{1}$.

При этом в СРЛЯ возможна иная достаточно частотная позиция, в которой на первый взгляд есть условия для нейтрализации и полной утраты «свистящего» согласного в позиции перед мягким «шипящим». Это позиция стыка слова, оканчивающегося на морф -сь (вариант постфикса -cя/-cb, использующийся «в позиции после морфов, оканчивающихся на гласную фонему (кроме флексийных падежных морфов)» [9. С. 125]), со следующим за ним словом, начинающимся с корневого мягкого «шипящего». В результате ассимиляции по месту образования, имеющей в СРЛЯ в позиции внешнего сандхи факультативный характер [1. С. 987; 5. С. 87], в таких сочетаниях слов образующийся на месте сочетания согласных «шипящий» должен утрачивать «тройную» длительность, на фонетическом уровне реализуясь обычным долгим [ш':] ([ш'\#ш'] $)^{2}$. Таким образом, акустические следы «свистящего» могут

${ }^{1} \Gamma$. Коутс [6] использует эти языковые факты в качестве одного из аргументов в пользу полифонемной трактовки мягкого «шипящего» (наиболее полно представлена в работах М. Флайера [7. С. 296-351]), поскольку указанные предлог и приставка ведут себя аналогичным образом перед консонантными кластерами. Оставляя в стороне эту дискуссию, отметим, что на синхронном уровне вокализация позволяет избежать нейтрализации в потенциально возможных и обнаруживаемых при поиске по Национальному корпусу русского языка [8] минимальных парах: с щеками* - щеками, сщемить - щеемить и т. д.

${ }^{2}$ Возможно, впрочем, коартикуляционные правила действуют в ином порядке: сначала мягкий «шипящий» утрачивает долготу, а затем происходит ассимиляция по месту об- 
полностью утрачиваться, и сочетание слов проявилась щедрость может быть неотличимо при восприятии от сочетания без постфикса: проявила щедрость.

Необходимо отметить, что указанная позиция нейтрализации возникла в СРЛЯ сравнительно недавно. Произношение мягкого «свистящего» в возвратном постфиксе получило широкое распространение в литературном произношении только в середине XX в.; «на протяжении всего XIX и в начале $\mathrm{XX}$ в. по литературной норме частицы -cя/-cb произносились с твердым [c]» [11. С. 103]. Таким образом, в первой половине прошлого века подобная нейтрализация еще не была возможной. Ей препятствовало отсутствие межсловной ассимиляции по твердости / мягкости (т.е., вероятно, в примере проявилась щеедрость на стыке слов звучало сочетание [с\#ш'] или, в случае ассимиляции по месту образования, [ш\#ш'], но не однородный долгий [ш'\#ш']). В настоящее время произношение [c] в постфиксе в позиции после гласного «расценивается как устарелое» [1. С. 993].

\section{2. Цели и методы исследования. Описание Эксперимента 1}

Настоящее исследование преследовало две основные цели. Во-первых, изучалась реализация мягкого переднеязычного зубного щелевого согласного на конце фонетического слова в позиции перед мягким переднеязычным передненебным глухим щелевым в речи носителей младшей нормы литературного произношения. В частности, исследовалась возможность ассимиляции согласных по месту образования и сокращения длительности «шипящего» в этом сочетании, приводящих к образованию единого долгого «шипящего». Во-вторых, ставилась цель проверить, может ли осуществление описанных коартикуляционных процессов приводить к полной нейтрализации минимальных пар типа проявилась щедрость - проявила щеедрость в восприятии носителей СРЛЯ.

Для достижения указанных целей был проведен фонетический эксперимент (Эксперимент 1), в ходе которого от 20 информантов, носителей литературного произношения в возрасте от 18 до 40 лет (10 мужчин и 10 женщин), был записан набор фраз. Участники эксперимента без подготовки читали вслух с экрана компьютера специально подготовленные фразы (стимулы), перемешанные в случайном порядке и представленные на отдельных слайдах. Некоторые из этих фраз включали тестовые сочетания слов: помимо сочетаний проявилась щедрость и проявила щедрость, были записаны следующие минимальные пары: сльшала щебетание и сльшалось щебетание; зажсли щеепки и зажслись щуепки; нашли щииты и нашлись щуиты; прижала щекой и прижалась щекой; сльшали щелчки и сльшались щелчки; обнаружила щзель и обнаружилась щзель. Кроме этого, в материал эксперимента была включена одна пара примеров со смычным переднеязычным согласным, который способен реализовываться «нулем звука» и тем самым может не пре-

разования: /с'\#ш':/ > /с'\#ш'/ > [ш'\#ш']. Такое предположение, однако, будет противоречить существующей в СРЛЯ закономерности, выявленной С.В. Князевым: «...правила ассимиляции в русском языке действуют одними из первых» [10. С. 139]. 
пятствовать ассимиляции по месту образования ${ }^{1}$ сммелость щенка вместе с контрастной парой сме́ло щзенка (забирать).

При составлении стимулов учитывались следующие фонетические факторы:

1. Состав согласных в исследуемом кластере. Выше уже было указано, что, помимо сочетания «свистящий» + «шипящий», был записан один пример с «непроизносимым» смычным согласным (смелость щенка).

2. Соседние по отношению к кластеру звуки. Как видно из приведенного выше списка примеров, все консонантные сочетания записывались в интервокальной позиции.

3. Акцентная структура примеров. Известно, что темпоральные характеристики согласных СРЛЯ зависят от положения звуков относительно ударных гласных (см. экспериментальные данные о щелевых переднеязычных в [3], о взрывных - в [13]). В настоящей работе при подборе стимулов выбирались пары словосочетаний с разными акцентными структурами. Исследуемые кластеры были записаны во всех возможных позициях: между ударными гласными, после ударного гласного перед безударным, после безударного перед ударным и между безударными гласными. Сравнение длительности согласных в разных позициях не входило в цели настоящей работы, однако влияние этого фактора учитывалось при анализе записей: абсолютная длительность звуков сравнивалась только попарно, для примеров с одинаковой акцентной структурой.

4. Позиция тестового сочетания слов во фразе. Согласно данным эксперимента, описанного в [14], на наличие / отсутствие ассимиляции переднеязычных согласных по месту образования на стыках фонетических слов может оказывать влияние место фразового акцента: при просодическом выделении первого слова в сочетании «чередование происходит значительно реже, чем в словосочетаниях с акцентно слабым первым словом» [Там же. С. 199]. В настоящей работе фразы, предложенные для прочтения информантам, подбирались таким образом, чтобы избежать фразового акцента на тестовых сочетаниях слов, все сочетания записывались внутри синтагмы. В том случае, если диктор в процессе чтения ошибочно, с точки зрения экспериментатора, членил фразу на синтагмы (например, делал лишнюю паузу или неверно ставил фразовый акцент), запись примера признавалась нерелевантной для анализа.

Записи 20 дикторов были проанализированы с использованием компьютерной программы Praat [15]. Релевантными для целей эксперимента были признаны 302 из 320 произнесений $(94,4 \%)$. При анализе осциллограмм и динамических спектрограмм фиксировались два параметра исследуемого сегмента фрикативного шума: спектральные характеристики и длительность. Спектральные характеристики (а именно равномерность нижней границы фрикативного шума на динамической спектрограмме) фиксировались для того, чтобы разделить записи с наличием / отсутствием ассимиляции по мес-

${ }^{1}$ Утрата смычного в подобных кластерах происходит почти регулярно; как указывает Г.А. Баринова, «вероятно, самая возможность и стремление к ассимиляции подталкивает процесс выпадения центрального согласного» (ср. также: гво[ж'] железный, в ше[ж'] же кончают) [12. С. 109]. 
ту образования согласных. Впоследствии результаты этого разделения были проверены с помощью перцептивного эксперимента. Длительность согласных измерялась в миллисекундах (мс) с округлением до десятых, за начало и конец щелевого согласного принимались начало и конец непериодических колебаний на осциллограмме, обычно соответствовавшие концу и началу второй форманты соседних гласных на динамической спектрограмме.

\section{3. Результаты Эксперимента 1}

Проведенный анализ записей фраз, включающих тестовые сочетания слов, подтвердил, что наличие / отсутствие ассимиляции переднеязычных щелевых согласных по месту образования в позиции внешнего сандхи зависит от индивидуальных особенностей диктора. В речи 6 дикторов-мужчин была зафиксирована регулярная полная ассимиляция «свистящих» «шипящими» (нижняя граница фрикативного шума на спектрограмме равномерная на протяжении всего звука, пример приведен на рис. 1; для сравнения см. рис. 2 , где в произношении того же стимула другим диктором нижняя граница шума неравномерна, ассимиляция отсутствует). В речи остальных 14 дикторов отмечена факультативность действия этого коартикуляционного правила (для каждого информанта зафиксировано не менее чем по одному произнесению как [c'ш'], так и [ш':]). Отдельно необходимо отметить, что в тестовом сочетании слов со смычным смелость щеека в произнесении 19 из 20 участников эксперимента смычный был утрачен; в 16 из 19 примеров за утратой смычного последовала ассимиляция «по месту».
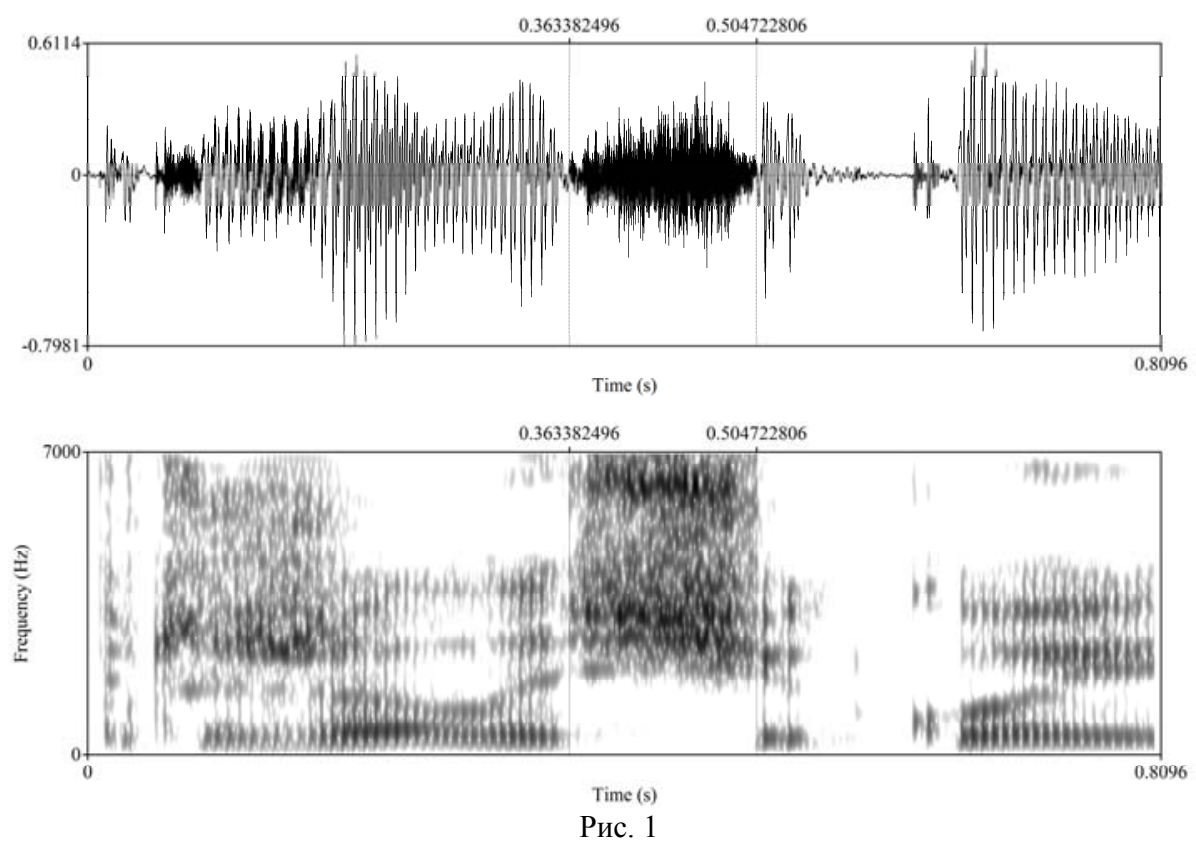

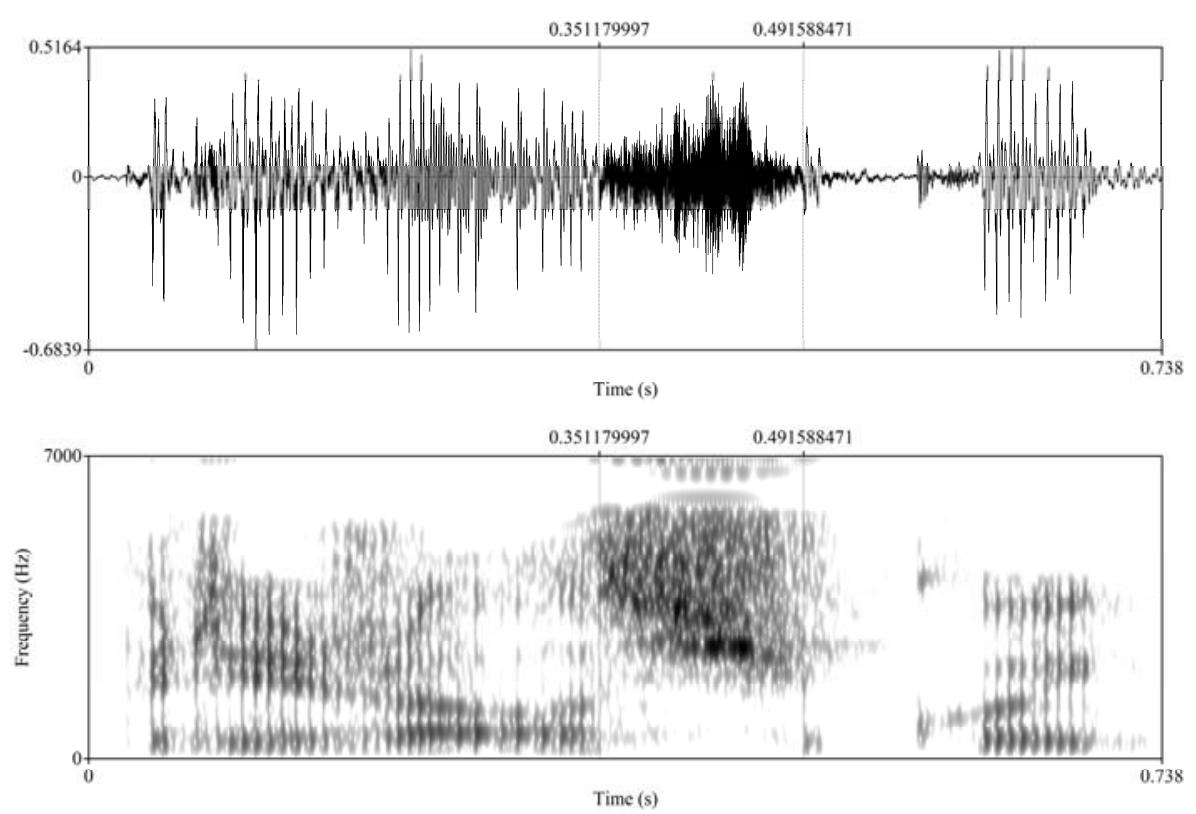

Рис. 2

В целом в 147 релевантных для анализа произнесений было зафиксировано 116 случаев полной ассимиляции согласных по месту образования (78,9\%). Похожий результат (76\%) был ранее зафиксирован для мягких согласных в другом эксперименте, в котором, в частности, исследовалось влияние твердости / мягкости конечного «свистящего» на его ассимиляцию начальным «шипящим» следующего слова. Тогда выяснилось, что на стыках фонетических слов «мягкий зубной щелевой значительно чаще ассимилируется последующим передненебным щелевым (как твердым, так и мягким), чем соответствующий твердый: ассимиляция [c'] в конце фонетического слова была зафиксирована в 81 из 106 произнесений (76\%), ассимиляция [c] лишь в 30 из 102 произнесений (29\%)» [16. С. 72].

Измерение абсолютной длительности «шипящих» показало, что этот параметр может колебаться в широких пределах. Так, для группы примеров с «глубинным» /c'/ (далее условно названы примерами Группы 1) при полной ассимиляции «свистящего» длительность звука составила в соседстве с одним или двумя ударными гласными от 111,8 до 296,5 мс; в соседстве с безударными гласными - от 105,1 до 233 мс. Для группы примеров с отсутствием /c'/ на словесной границе (далее - Группы 2) длительность щелевого составила в соседстве с одним или двумя ударными гласными от 98,7 до 213,1 мс; в соседстве с безударными гласными от 88,9 до 232,4 мс.

Однако для целей настоящего эксперимента измерения абсолютной длительности фрикативных щелевых, образующихся в результате полной ассимиляции «свистящих» «шипящими», представляли лишь опосредованный интерес, поскольку они в крайне высокой степени зависят не только от положения этих звуков относительно ударных гласных, но и от индивидуальных 
особенностей дикторов, в частности темпа речи. Главным параметром, представлявшим интерес в контексте изучения потенциальной нейтрализации /с'\#ш':/ и /\#ш':/, послужила разность в длительности фрикативного шума между примерами из Группы 1 и Группы 2. Важно добавить, что разность подсчитывалась для каждой релевантной для анализа пары примеров отдельно, т.е. в каждом случае сравнивалось произнесение «шипящего» одним и тем же диктором в «минимальных парах» (сочетаниях слов, имеющих одинаковый звуковой состав, за исключением наличия или отсутствия глубинного /c'/ перед словесной границей, и одинаковую акцентную структуру).

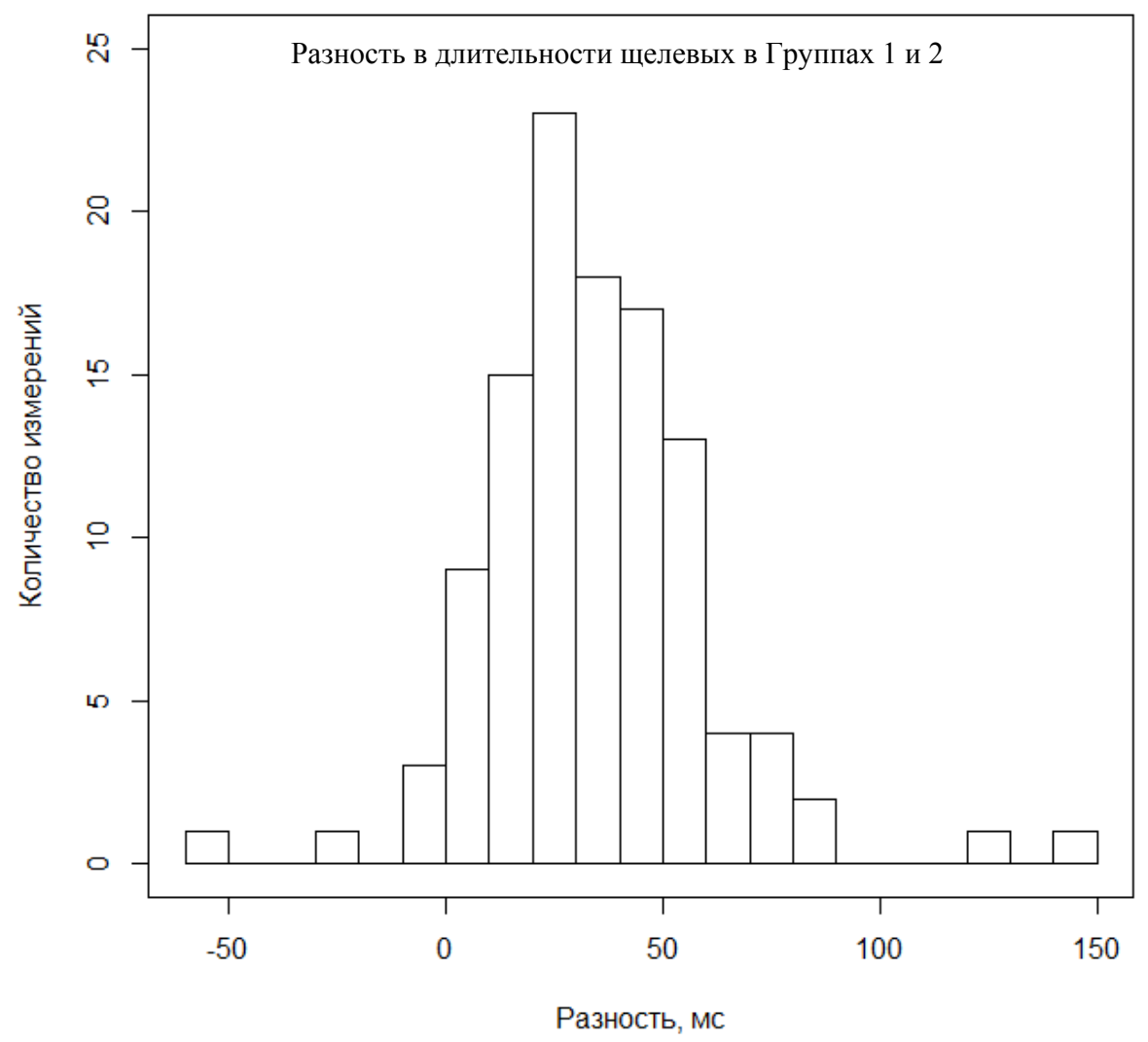

Рис. 3

Результаты попарного подсчета разности в длительности между «шипящими» в примерах Групп 1 и 2 представлены в абсолютных величинах в виде гистограммы на рис. 3. Количество релевантных для анализа пар (т.е. таких пар, в которых произнесение примеров Группы 1 и 2 было признано релевантным для анализа, при этом в примере Группы 1 наблюдалась полная ассимиляция по месту образования) составило 112. В подавляющем большинстве пар (107 из 112; 95,5\%) разность оказалась положительной; таким образом, во всех этих парах в произношении «минимальной пары» одним и тем же диктором длительность [ш':] на месте /с'\#ш':/ оказывалась больше, чем 
длительность [ш':] на месте /\#ш':/. На рис. 4 те же данные представлены в относительных величинах. В релевантных для анализа парах было посчитана в процентах длительность фрикативного шума в примерах Группы 1 по отношению к длительности фрикативного шума в примерах Группы 2 (таким образом, например, $120 \%$ означает, что согласный на месте /с'\#ш':/ оказался на $20 \%$ более долгим, чем согласный на месте /\#ш':/ в произношении контрастного примера тем же диктором).

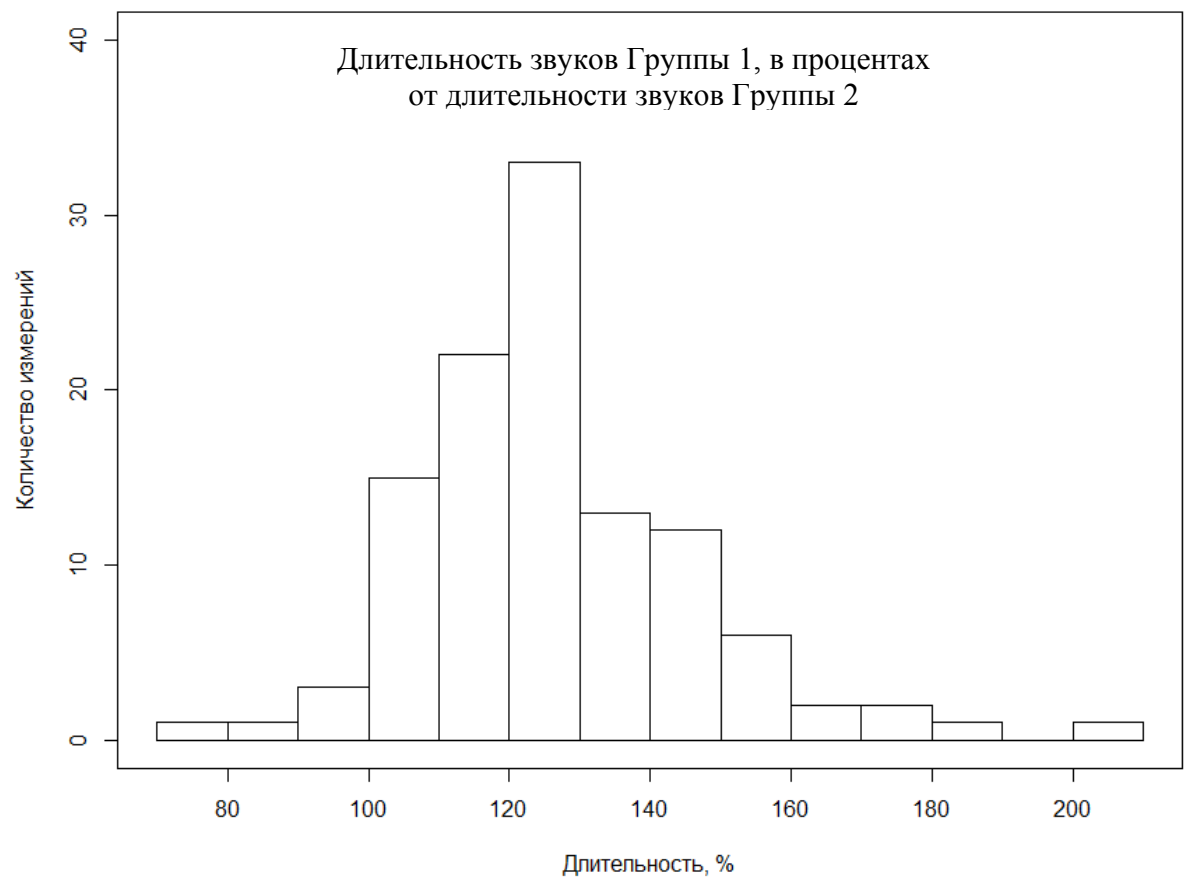

Рис. 4

В среднем согласные в примерах Группы 1 с ассимиляцией обладали на 34,9 мс (стандартное отклонение - 25,9), или 26\% (стандартное отклонение $19,4)$ большей длительностью по сравнению с согласными Группы 2. Статистический анализ полученных данных подтвердил гипотезу о том, что различия между длительностью «шипящих» в примерах разных групп являются значимыми. Для проверки гипотезы использовался парный t-критерий Стьюдента: $\mathrm{t}(56)=-10,044 ; \mathrm{p}<0,001$.

\section{4. Перцептивный эксперимент (Эксперимент 2) и его результаты}

С целью установить, могут ли выявленные в рамках Эксперимента 1 различия в длительности щелевых согласных служить в восприятии носителей СРЛЯ сигналами о наличии или отсутствии /c'/ на словесной границе, был проведен перцептивный эксперимент (Эксперимент 2). В ходе него 15 информантам, студентам Школы лингвистики Высшей школы экономики в возрасте 17-19 лет, были предложены для прослушивания 35 тестовых сочета- 
ний слов, вырезанных из фразового контекста. Каждое сочетание предлагалось к прослушиванию дважды, интервал между двумя воспроизведениями одного и того же примера составлял 5-10 секунд. Все тестовые сочетания можно классифицировать следующим образом:

1. Примеры Группы 1 с ассимиляцией по месту образования, см., например, рис. 1 (12 стимулов, длительность фрикативного шума от 141 до 202 мс).

2. Примеры Группы 1 без ассимиляции по месту образования, т. е., с неоднородной нижней границей фрикативного шума на спектрограмме, см., например, рис. 2 (12 стимулов, длительность фрикативного шума от 134 до $245 \mathrm{Mc})$.

3. Примеры Группы 2 (11 стимулов, длительность фрикативного шума от 135 до 198 мс).

Эксперимент 2 может быть условно разделен на три этапа. На первом этапе информантам было предложено 10 стимулов. Участники не были проинформированы о целях эксперимента, им предлагалось зафиксировать услышанные сочетания слов в орфографической записи на чистых бланках, таким образом, в ходе этого этапа проверялось не только то, как носители СРЛЯ воспринимают длительность «шипящих» на стыках слов, но и то, могут ли вообще информанты корректно интерпретировать предложенные стимулы.

После первого этапа участники эксперимента получили общее представление о стимульном материале, поэтому на втором и третьем этапах их задача была несколько упрощена: им предлагались бланки иного образца, с выбором предпочтительного варианта. Предлагалось выбрать наиболее соответствовавшее услышанному стимулу сочетание слов из двух вариантов (например, зажсли щуепки или зажслись щуепки).

Второй этап перцептивного эксперимента, включивший 12 стимулов, в основном преследовал цель проверить восприятие тех примеров, в которых на основании анализа динамических спектрограмм было зафиксировано отсутствие ассимиляции щелевых по месту образования. Для этого информантам предлагались к прослушиванию в произвольном порядке примеры с наличием и отсутствием ассимиляции, а также примеры Группы 2 (с отсутствием «свистящего»). Следует уточнить, что отдельные примеры с отсутствием ассимиляции были также включены в первый и третий этап, чтобы информанты не чувствовали резкого перехода между частями эксперимента.

Наконец, третий этап перцептивного эксперимента (13 стимулов) был в основном ориентирован на выявление способности информантов различать примеры Группы 1 и Группы 2 при осуществлении полной ассимиляции «свистящих» «шипящими». Как и на первом этапе, в основном к прослушиванию предлагались как примеры Группы 1 с полной ассимиляцией «по месту», так и некоторое количество примеров Группы 2.

Информанты в целом корректно воспринимали предложенные сочетания слов, что продемонстрировал анализ первого бланка ответов: на первом этапе лишь в 15 случаях (10\%) участники не смогли записать услышанное или записали словосочетание неверно (например, записывали не зажгли щееки или зажглись щепки, а нечто совершенно иное). 
Реакция информантов на 12 стимулов, в которых предполагалось отсутствие ассимиляции по месту образования (иными словами, произнесение [c'ш']), в целом подтвердила корректность решений, принятых на основании анализа динамических спектрограмм. В 161 из 179 случаев $(89,9 \%)$ участники эксперимента воспринимали присутствие «свистящего». При этом материал эксперимента не позволил обнаружить четкой зависимости между длительностью этих неоднородных участков фрикативного шума и их восприятием: небольшие колебания были зафиксированы в примерах как с малой длительностью кластера, так и с большой.

Наиболее ценные для настоящего исследования результаты были получены в ходе анализа реакции участников эксперимента на примеры с полной ассимиляцией «свистящих» «шипящими». При восприятии примеров Группы 1 с ассимиляцией по месту образования участники эксперимента указали наличие «свистящего» в 90 из 177 случаев (50,8\%). При восприятии примеров Группы 2, в которых /c'/ отсутствует на фонемном уровне, участники верно указали отсутствие «свистящего» лишь немногим чаще: в 88 из 154 случаев (57,1\%). При этом колебания наблюдались в интерпретации всех без исключения стимулов, и зависимости реакции каждого из информантов от длительности исследуемых щелевых согласных обнаружить не удалось.

Таким образом, поскольку вероятность каждого из возможных ответов при случайном выборе составляла $50 \%$, полученные данные можно использовать как свидетельство в пользу того, что участники эксперимента при восприятии стимулов не могли отличить примеры Группы 1 от примеров Группы 2, а при принятии решений не использовали в качестве критерия длительность фрикативного шума.

\section{5. Обсуждение}

Проведенное исследование позволяет сделать вывод о фонетической реализации сочетания «глухой мягкий щелевой зубной» + «глухой мягкий щелевой передненебный» на стыке фонетических слов в СРЛЯ. Анализ записей 20 дикторов, носителей литературного произношения, подтвердил, что в указанных кластерах наблюдается факультативная ассимиляция по месту образования. Перцептивный эксперимент продемонстрировал, что в том случае, если на динамической спектрограмме и осциллограмме наблюдается неоднородность фрикативного шума (в частности, изменение нижней границы шума на спектре), носители СРЛЯ получают из акустического сигнала информацию о наличии /с'/ на словесной границе.

Измерения длительности фрикативного шума показали, что щелевые согласные, образующиеся в результате полной ассимиляции «свистящих» «шипящими» на месте /c'\#ш':/, обладают большей длительностью, чем одиночные щелевые согласные в начале слова после гласного - /\#ш':/. При попарном сравнении произнесений минимальных пар одним и тем же диктором выяснилось, что согласный на месте /с'\#ш':/ был более долгим, чем согласный на месте /\#ш':/, в 95,5\% случаев. В среднем при таком попарном сопоставлении согласные на месте консонантных кластеров оказались на 34,9 мс, или $26 \%$, более долгими, чем согласные на месте одиночного «шипящего». 
При этом проведенный перцептивный эксперимент продемонстрировал, что носители СРЛЯ при восприятии не пользуются этим различием: вне фразового контекста ${ }^{1}$ они могут интерпретировать звук [ш'(:)] на стыке фонетических слов как одиночный «шипящий» или как последовательность «свистящий»+ «шипящий». При этом на их решение не оказывает заметного влияния длительность звука, которая в стимулах колебалась в широких пределах от 135 до 202 мс. Вероятно, такое «безразличие» носителей языка к темпоральным характеристикам мягкого «шипящего» связано с тем, что избыточная длительность этого звука в СРЛЯ крайне нестабильна (по сравнению с длительностью других согласных русского языка, в частности твердого «шипящего») и может регулярно сокращаться в зависимости от позиции согласного относительно ударных гласных, других согласных и словесных границ (начало / конец фонетического слова).

Полученные экспериментальные данные могут служить свидетельством в пользу того, что в СРЛЯ в описанной позиции имеет место неполная нейтрализация одиночного мягкого «шипящего» /\#ш':/ и кластера /c'\#ш':/. Неполная нейтрализация (англ. incomplete neutralization) - это разновидность фонологической нейтрализации (неразличения двух и более фонем в определенной позиции), при которой на фонетическом уровне сохраняются следы противопоставления. Явление «неполной нейтрализации» в основном описано в фонетической литературе в связи с конечным оглушением шумных согласных, в частности, примером является немецкий язык, в котором традиционно считаются омофонами такие пары слов, как Rat 'совет' и Rad 'колесо', однако анализ записей произношения минимальных пар носителями языка показывает, что акустические характеристики звуков в Rad и Rat не идентичны.

Исследования неполной нейтрализации, начавшиеся в 1980-х гг. [17, 18], продолжаются, все больше внимания уделяется методологическим трудностям обнаружения этого явления, в том числе влиянию орфографии. Так, серия экспериментов [19], проведенных на материале немецкого языка, вновь подтвердила, что в немецком языке длительность гласного, предшествующего конечному в слоге смычному шумному согласному, коррелирует с глухостью / звонкостью этого согласного. Гласный в позиции перед оглушенным согласным имеет большую длительность, нежели гласный перед глухим согласным. Перцептивный эксперимент показал, что при восприятии носители языка верно различали оглушенные и глухие согласные лишь в 55\% случаев, причем даже эта невысокая точность достигалась в основном за счет идентификации глухих согласных, а оглушенные согласные верно идентифицировались примерно в 50\% случаев (ср. похожие результаты перцептивного эксперимента в настоящем исследовании, где точность выше 50\% была достигнута только за счет верной идентификации примеров без /с'/).

\footnotetext{
${ }^{1}$ Необходимо отметить, что в большинстве случаев образующаяся в результате фонетических процессов неоднозначность устраняется за счет контекста. Однако в некоторых синтаксических конструкциях возможно и сохранение неоднозначности, ср.: $B$ печке зажәлись щепки и односоставное предложение $B$ печке зажгли щепки.
} 
Оглушение конечных шумных согласных в СРЛЯ также становилось объектом исследований, посвященных неполной нейтрализации. Темпоральные различия глухих и оглушенных шумных согласных в позиции конца слова (меньшая длительность оглушенных согласных по сравнению с глухими), а также предшествующих им гласных (аналогично немецкому языку, см. выше) были впервые продемонстрированы на материале русского языка в работе [20]. Последовательные различия в длительности были обнаружены для гласных, предшествующих всем парным по глухости / звонкости шумным согласным, за исключением взрывных зубных. Впоследствии в работе [21] эта лакуна была заполнена: автору исследования удалось обнаружить различие в длительности гласных перед глухим /т/ и оглушенным /д/, при этом было отмечено, что в отличие от германских языков в славянских носителями наиболее заметных акустических различий при неполной нейтрализации являются не гласные, а согласные (такими параметрами являются длительность взрывной части, смычки и озвонченной части смычки - voicing into closure).

В проводившемся параллельно эксперименте [22] были получены похожие результаты; кроме того, было обнаружено влияние владения английским языком на носителей русского языка: в отличие от монолингвов, владевшие английским языком на продвинутом уровне русскоязычные дикторы при произношении глухих и оглушенных согласных использовали различия не только в длительности согласного, но и в длительности гласного и озвонченной части смычки или фрикативного шума. Наконец, в работах В. Харламова $[23,24]$ также сделан вывод о том, что в речи носителей СРЛЯ неполная нейтрализация при оглушении достигается за счет темпоральных характеристик согласных, а не гласных; кроме того, было описано влияние орфографии, наличия / отсутствия минимальных пар и методологических факторов на произношение и восприятие глухих и оглушенных согласных носителями СРЛЯ.

Результаты настоящего исследования демонстрируют, что неполная нейтрализация в СРЛЯ может иметь место не только при оглушении конечных согласных, но и при сокращении длительности мягкого «шипящего» в сочетаниях, образующихся в результате ассимиляции мягких щелевых согласных по месту образования на стыках фонетических слов. Проведенный эксперимент показал, что в парах типа проявилась щедрость и проявила щедрость образующиеся в результате ассимиляции двух звуков по месту образования долгие «шипящие» последовательно обладают большей длительностью, чем звуки на месте одиночного «шипящего» в интервокальной позиции. При этом носители СРЛЯ при восприятии не пользуются этими темпоральными различиями и, как следствие, не различают эти пары сочетаний слов на слух в том случае, если осуществляется полная ассимиляция по месту образования. Таким образом, в восприятии носителей языка одиночный /\#ш':/ нейтрализован с кластером /с'\#ш':/, однако на фонетическом уровне нейтрализация является неполной ввиду последовательных различий в длительности согласных.

В заключение необходимо подчеркнуть, что объектом настоящего исследования послужили только сочетания, образующиеся в позиции «внешнего сандхи». Полученные результаты позволяют предположить, что аналогичные темпоральные различия могут быть обнаружены и между мягкими шипящи- 
ми в позиции «внутреннего сандхи», на стыках морфем. Представляется продуктивным сравнить, например, [ш'(:)] в похожих контекстах в парах типа расщепить - защемить (а также, возможно, подписчик-ящик). Однако даже если темпоральные различия будут обнаружены, проведение перцептивного эксперимента, призванного выяснить влияние этих акустических различий на восприятие носителей СРЛЯ, будет затруднено в связи с отсутствием минимальных пар.

\section{Литература}

1. Каленчук М. Л., Касаткин Л. Л., Касаткина Р. Ф. Большой орфоэпический словарь русского языка. Литературное произношение и ударение начала XXI века: норма и ее варианты. М.: АСТ-ПРЕСС, 2012. $1008 \mathrm{c}$.

2. Timberlake A. A Reference Grammar of Russian. Cambridge: Cambridge University Press, 2004. $503 \mathrm{p}$.

3. Kochetov A. Acoustics of Russian Voiceless Sibilant Fricatives // Journal of the International Phonetic Association. 2017. P. 1-28. DOI:10.1017/S0025100317000019.

4. Аванесов Р. И. Русское литературное произношение. М.: Просвещение, 1984. 383 с.

5. Панов М. В. Русская фонетика. М.: Просвещение, 1967. 440 с.

6. Coats, H. S. On the phonemic status of Russian [ك'`':] // Russian Linguistics. 1997. № 21(2). P. $157-164$.

7. Флайер М. Избранные труды. Т. 1: Работы по синхроническому языкознанию. М.: Языки славянской культуры, 2010. 696 с.

8. Наииональный корпус русского языка. URL: http://www.ruscorpora.ru (дата последнего обращения: 11.04.2017).

9. Русская грамматика. Т. 1: Фонетика. Фонология. Ударение. Интонация. Словообразование. Морфология / Н.Ю. Шведова (гл. ред.). М.: Наука, 1980. 789 с.

10. Князев С.В. Об иерархии фонологических правил в русском языке (несколько новых соображений по поводу язв А.А. Реформатского) // Семиотика, лингвистика, поэтика: К столетию со дня рождения А.А. Реформатского. М., 2004. С. 133-150.

11. Русский язык и советское общество: Социолого-лингвистическое исследование. Фонетика современного русского литературного языка. Народные говоры / АН СССР. Ин-т рус. яз.; под ред. М.В. Панова. М.: Наука, 1968. 213 с.

12. Баринова Г.А. Редукция гласных в разговорной речи // Развитие фонетики современного русского языка. М.: Наука, 1971. С. 97-116.

13. Zsiga E.C. Phonetic alignment constraints: Consonant overlap and palatalization in English and Russian // Journal of Phonetics. 2000. № 28(1). P. 69-102.

14. Гусева M.E. О некоторых фонетических явлениях на стыках слов в современном литературном русском языке // Проблемы фонетики, IV. М., 2002. С. 196-200.

15. Boersma P., Weenink, $D$. Praat: doing phonetics by computer [Computer program]. Version 6.0.22 retrieved 25.11.2016 from http://www.praat.org/

16. Дурягин П. В. Коартикуляционные изменения согласных по месту и способу образования на стыках слов в современном русском литературном языке: дис. ... канд. филол. наук. M., 2016. $212 \mathrm{c}$.

17. Port R., O'Dell M. Neutralization of syllable-final voicing in German // Journal of Phonetics. 1985. № 13(4). P. 455-471.

18. Dinnsen D.A., Charles-Luce J. Phonological neutralization, phonetic implementation and individual differences // Journal of Phonetics. 1985. № 12 (1). P. 49-60.

19. Roettger T.B., Winter B., Grawunder S., Kirby J., Grice M. Assessing incomplete neutralization of final devoicing in German // Journal of Phonetics. 2014. № 43(1). P. 11-25.

20. Pye S. Word-final devoicing of obstruents in Russian // Cambridge Papers in Phonetics and Experimental Linguistics. 1986. № 5. P. 1-10.

21. Shrager M. Neutralization of word-final voicing in Russian // Journal of Slavic Linguistics. 2012. № 20. P. 71-99.

22. Dmitrieva O., Jongman A., Sereno $J$. Phonological neutralization by native and non-native speakers: The case of Russian final devoicing // Journal of Phonetics. 2010. № 38(3). P. 483-492. 
23. Kharlamov $V$. Incomplete neutralization of the voicing contrast in word-final obstruents in Russian: Phonological, lexical, and methodological influences // Journal of Phonetics. 2014. № 43(1). P. 47-56.

24. Kharlamov $V$. Perception of incompletely neutralized voicing cues in word-final obstruents: The role of differences in production context // Laboratory Phonology. 2015. 2015. № 6(2). P. 147-165.

\section{INCOMPLETE NEUTRALISATION AS A RESULT OF PLACE ASSIMILATION OF PALA- TALISED SIBILANTS AT WORD BOUNDARIES IN MODERN STANDARD RUSSIAN}

Vestnik Tomskogo gosudarstvennogo universiteta. Filologiya - Tomsk State University Journal of Philology. 2017. 50. 55-69. DOI: 10.17223/19986645/50/4

Pavel V. Duryagin, Higher School of Economics (Moscow, Russian Federation). E-mail: pavelustug@mail.ru

Keywords: Modern Standard Russian, phonetics, external sandhi, coarticulation, fricatives, place assimilation, incomplete neutralisation.

The paper describes a phonetic experiment that dealt with the place assimilation of voiceless palatalised alveolar fricative $/ \mathrm{s}^{\mathrm{j}} /$ by following postalveolar alveo-palatal fricative /6:/ at word boundaries in Modern Standard Russian. As the former sibilant is commonly described as a geminated sound and Russian prohibits long consonants in positions near other consonants, the assimilation process can potentially lead to neutralisation in such minimal pairs of word combinations as proyavila shchedrost' [(she) showed generosity] and proyavilas' shchedrost' [generosity showed itself].

The participants of the experiment, 20 native Russian speakers (10 men and 10 women aged 18 to 40 ), were instructed to read a list of sentences that included 8 minimal pairs of target word combinations embedded in carrier phrases. All stimuli were recorded in intervocalic position; phrasal accent on stimuli was avoided; accent structure of the target word combinations was deliberately varied (clusters were recorded in all possible positions with regard to stressed and unstressed vowels).

All recordings were analysed using computer software Praat. The duration and homogeneity of fricative noise were measured. Spectral analysis showed that in $78 \%$ of cases place assimilation of sibilants at word boundaries was complete. The measurements of duration confirmed that this parameter could vary widely, mostly in connection with stress. The duration of [c(:)] sounds within minimal pairs pronounced by the same speaker showed that in similar conditions in $95.5 \%$ of cases the sound representing the underlying $/ \mathrm{s}^{\mathrm{j}} \#_{6}: /$ was longer than the surface representation of the underlying $/ \#_{6}: /$ (mean difference $34,9 \mathrm{~ms}$; mean duration ratio 1,26 ).

In order to find out whether these durational differences can be used by native speakers to distinguish minimal pairs a perception experiment was conducted. 15 native speakers, students aged 17-19, were presented with 35 stimuli (word consequences recorded during the described above experiment, but removed from phrasal context; the duration of the fricative varied widely from 135 to $202 \mathrm{~ms}$ ). The participants' task was to write down what they think they heard. Their responses demonstrated that they could not reliably distinguish tokens with place assimilation of underlying $/ \mathrm{s}^{\mathrm{j}} /$ (the number of correct guesses was at a chance rate $-50.8 \%$ ) and tokens without underlying $/ \mathrm{s}^{\mathrm{j}} /$ (the number of correct guesses was only slightly larger $-57.1 \%$ ) despite the significant durational differences.

The described phenomenon can be interpreted as a case of incomplete neutralisation. The experiments showed that the neutralisation of / $\# 6: /$ and $/ \mathrm{s}^{\mathrm{j}} \# 6 \mathrm{6}: /$ at word boundaries in Russian is phonetically incomplete due to the significant durational differences between the produced fricatives, although these acoustic cues were not used by native speakers in distinguishing minimal pairs.

\section{References}

1. Kalenchuk, M.L., Kasatkin, L.L. \& Kasatkina, R.F. (2012) Bol'shoy orfoepicheskiy slovar' russkogo yazyka. Literaturnoe proiznoshenie $i$ udarenie nachala XXI veka: norma $i$ ee varianty [A large orthoepic dictionary of the Russian language. Literary pronunciation and stress of the beginning of the 21 st century: the norm and its variants]. Moscow: AST-PRESS

2. Timberlake, A. (2004) A Reference Grammar of Russian. Cambridge: Cambridge University Press.

3. Kochetov, A. (2017) Acoustics of Russian Voiceless Sibilant Fricatives. Journal of the International Phonetic Association. pp. 1-28. DOI:10.1017/S0025100317000019 
4. Avanesov, R.I. (1984) Russkoe literaturnoe proiznoshenie [Russian literary pronunciation]. Moscow: Prosveshchenie.

5. Panov, M.V. (1967) Russkaya fonetika [Russian phonetics]. Moscow: Prosveshchenie.

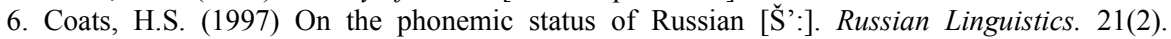
pp. 157-164.

7. Flyer, M. (2010) Izbrannye trudy [Selected works]. Vol. 1. Translated from English. Moscow: Yazyki slavyanskoy kul'tury.

8. Russian Language National Corpus. [Online] Available from: http://www.ruscorpora.ru. (Accessed 11.04.2017). Nauka.

9. Shvedova, N.Yu. (ed.) (1980) Russkaya grammatika [Russian grammar]. Vol. 1. Moscow:

10. Knyazev, S.V. (2004) Ob ierarkhii fonologicheskikh pravil v russkom yazyke (neskol'ko novykh soobrazheniy po povodu yazv A. A. Reformatskogo) [On the hierarchy of phonological rules in the Russian language (several new considerations on the yazv of A.A. Reformatsky)]. In: Vinogradov, V.A. (ed.) Semiotika, lingvistika, poetika: $K$ stoletiyu so dnya rozhdeniya A.A. Reformatskogo [Semiotics, linguistics, poetics: To the centenary of the birth of A.A. Reformatsky]. Moscow: Yazyki slavyanskoy kul'tury.

11. Panov, M.V. (ed.) (1968) Russkiy yazyk i sovetskoe obshchestvo: Sotsiologo-lingvisticheskoe issledovanie. Fonetika sovremennogo russkogo literaturnogo yazyka. Narodnye govory [Russian language and Soviet society: Sociological and linguistic research. Phonetics of the modern Russian literary language. Folk dialects]. Moscow: Nauka.

12. Barinova, G.A. (1971) Reduktsiya glasnykh v razgovornoy rechi [Reduction of vowels in colloquial speech]. In: Glovinskaya, M.Ya. et al. Razvitie fonetiki sovremennogo russkogo yazyka [Development of phonetics of the modern Russian language]. Moscow: Nauka.

13. Zsiga, E.C. (2000) Phonetic alignment constraints: Consonant overlap and palatalization in English and Russian. Journal of Phonetics. 28(1). pp. 69-102.

14. Guseva, M.E. (2002) O nekotorykh foneticheskikh yavleniyakh na stykakh slov v sovremennom literaturnom russkom yazyke [On some phonetic phenomena at the junctions of words in the modern literary Russian language]. In: Kasatkina, R.F. (ed.) Problemy fonetiki [Problems of phonetics]. Vol. IV. Moscow: Nauka.

15. Boersma, P. \& Weenink, D. (n.d.) Praat: doing phonetics by computer [Computer program]. Version 6.0.22. [Online] Available from: http://www.praat.org/. (Accessed: 25.11.2016).

16. Duryagin, P.V. (2016) Koartikulyatsionnye izmeneniya soglasnykh po mestu i sposobu obrazovaniya na stykakh slov $v$ sovremennom russkom literaturnom yazyke [Co-articulate changes in consonants in place and way of formation at the joints of words in modern Russian literary language]. Philology Cand. Diss. Moscow.

17. Port, R. \& O'Dell, M. (1985) Neutralization of syllable-final voicing in German. Journal of Phonetics. 13(4). pp. 455-471.

18. Dinnsen, D.A. \& Charles-Luce, J. (1985) Phonological neutralization, phonetic implementation and individual differences. Journal of Phonetics. 12(1). pp. 49-60.

19. Roettger, T.B. et al. (2014) Assessing incomplete neutralization of final devoicing in German. Journal of Phonetics. 43(1). pp. 11-25.

20. Pye, S. (1986) Word-final devoicing of obstruents in Russian. Cambridge Papers in Phonetics and Experimental Linguistics. 5. pp. 1-10.

21. Shrager, M. (2012) Neutralization of word-final voicing in Russian. Journal of Slavic Linguistics. 20. pp. 71-99.

22. Dmitrieva, O., Jongman, A. \& Sereno, J. (2010) Phonological neutralization by native and non-native speakers: The case of Russian final devoicing. Journal of Phonetics. 38(3). pp. 483-492.

23. Kharlamov, V. (2014) Incomplete neutralization of the voicing contrast in word-final obstruents in Russian: Phonological, lexical, and methodological influences. Journal of Phonetics. 43(1). pp. $47-56$.

24. Kharlamov, V. (2015) Perception of incompletely neutralized voicing cues in word-final obstruents: The role of differences in production context. Laboratory Phonology. 6(2). pp. 147-165. DOI: $10.1515 / 1 p-2015-0005$ 